\title{
Pathways for scaling up public health interventions
}

\author{
Devon Indig ${ }^{1^{*}}$, Karen Lee ${ }^{2}$, Anne Grunseit ${ }^{1}$, Andrew Milat ${ }^{2,3}$ and Adrian Bauman ${ }^{1}$
}

\begin{abstract}
Background: To achieve population-wide health improvement, public health interventions found effective in selected samples need to be 'scaled up' and implemented more widely. The pathways through which interventions are scaled up are not well characterised. The aim of this paper is to identify examples of public health interventions which have been scaled up and to develop a conceptual framework which quantifies and describes this process.

Methods: A multi-stage international literature search was undertaken to identify examples of public health interventions in high income countries that have been scaled up or implemented at scale. Initial abstract review identified articles which met all the criteria of being a: 1) public health intervention; 2) chronic disease prevention focus; 3) program delivered at a wide geographical scale (state, national or international). Interventions were reviewed and coded into a conceptual framework pathway to document their scaling up process. For each program, an in-depth review of the identified articles was undertaken along with a broad internet based search to determine the outcomes of the dissemination process. A conceptual framework of scaling up pathways was developed that involved four stages (development, efficacy testing, real world trial and dissemination) to which the 40 programs were mapped.

Results: The search identified 40 public health interventions that showed evidence of being scaled up. Four pathways were identified to capture the different scaling up trajectories taken which included: 'Type I - Comprehensive' (55\%) which passed through all four stages, 'Type II - Efficacy omitters' (5\%) which did not conduct efficacy testing, Type III - Trial omitters' (25\%) which did not conduct a real world trial, and 'Type IV - At scale dissemination' (15\%) which skipped both efficacy testing and a real world trial.

Conclusions: This is the first study to classify and quantify the potential pathways through which public health interventions in high income countries are scaled up to reach the broader population. Mapping these pathways not only demonstrates the different trajectories that occur in scaling up public health interventions, but also allows the variation across scaling up pathways to be classified. The policy and practice determinants leading to each pathway remain for future study, especially to identify the conditions under which efficacy and replication stages are missing.
\end{abstract}

Keywords: Scaling up, Public health interventions, Program implementation

\section{Background}

In order to achieve population-wide health improvement, public health interventions found effective in a controlled research setting should be 'scaled up' and implemented more widely $[1,2]$. Scaling up refers to "deliberate efforts to increase the impact of successfully tested health interventions so as to benefit more people and to foster policy and program development on a

\footnotetext{
* Correspondence: d.indig@unsw.edu.au

${ }^{1}$ The Australian Prevention Partnership Centre and School of Public Health,

University of Sydney, Sydney, Australia

Full list of author information is available at the end of the article
}

lasting basis" [2]. The scalability of an intervention is determined by its effectiveness and by the likely reach and adoption of the intervention, the costs of operating at larger scale and the acceptability and fit of the intervention within the local policy context [3]. Unfortunately, the majority of published public health research remains focused on describing patterns of risk and disease, or describing results of controlled trials in highly selected samples, rather than providing evidence of the effectiveness of interventions at the population-level [4]. 
There is a growing literature describing operational frameworks for scaling up health interventions [2, 5-13]. These frameworks focus on providing advice to policymakers and funding agencies (mostly from low and middle income countries) about the steps needed to scale up an intervention. For example, in the framework developed by Milat (2014), the operational steps included: 1. Assessing whether the intervention is scalable; 2. Developing a scale up plan; 3 . Securing resources and preparing for scaling up; and 4. Scaling up the intervention using the developed plan $[10,11]$. Though operationally useful, these frameworks remain mostly theoretical with a limited number of case studies of best practice. There were no papers found which classified the scaling up pathways that were followed for a diverse range of real world program examples.

The aim of this paper is to review the literature to identify examples of public health interventions in high income countries that have been scaled up and to use them to develop a classification system to describe the pathways taken from program development to population-wide dissemination. We then apply this classification system to a sample of public health programs that have been scaled up to characterise the scaling up stages that take place in real world settings.

\section{Methods}

\section{Literature review search strategy}

We conducted a search of the peer review literature for examples of public health interventions focusing on the prevention of chronic diseases which have been scaled up. It should be noted that this literature search was not for the purpose of conducting a systematic review as such, but rather to identify indicative studies of programs which have been scaled up. The terminology used to identify potential examples of scaled up interventions included reference to 'scale', 'dissemination', 'diffusion', among other terms described in Table 1. Studies were included if they were published in English and conducted among humans from January 1990 to December 2014. A summary of the databases searched and search terms used are outlined in Table 1.
The literature review was conducted in June 2015. The initial search across the three databases and three search areas (area of focus, activity and condition type combined with 'OR') identified 7,495,029 and 6272 articles (combined with 'AND'), respectively (see Fig. 1). As the current evidence base is largely based on programs scaled up in low and middle income countries our review focused on chronic disease prevention programs in high income countries and studies that addressed scale up of cancer, HIV, maternal and child health and studies conducted in low income countries were excluded. The second stage involved an abstract review to determine which articles met all the criteria of being a: 1) public health intervention; 2) chronic disease prevention focus; 3) program delivered at a wide geographical scale (state, national or international). This review resulted in the exclusion of 5761 articles and a further 76 duplicates, resulting in 435 articles. A more detailed abstract appraisal left 155 articles, representing 60 individual programs that were further investigated for evidence of being scaled up and full review.

\section{Evidence of scaling up}

For each of the 60 of potentially scaled up programs identified, a detailed review of the associated papers was undertaken to determine the steps taken in program development, implementation and dissemination. This included reviewing other published articles on the same program (usually on prior pilot/efficacy studies) followed by a broad internet based search to determine the outcomes/end result of the dissemination process. The internet-based search was conducted on Google and/or Google scholar, using key words such as the: program name; chief investigator(s), program developer, author's name; and the funding or supporting agency or institution name (if known or relevant). If no further evidence of scaling up of programs identified in the initial review was found through these means, the program was flagged as 'outcome unknown'. Where websites were in languages other than English, the 'Google translate' feature was employed to determine the extent to which the program was still operational or not. This detailed review and search excluded a further 20 programs either

Table 1 Literature search criteria

\begin{tabular}{ll}
\hline Databases used & Medline, Embase, Informit \\
\hline Search terms included & 1. Area of focus: (Health promotion OR Public health OR Primary Prevention OR Secondary prevention) \\
AND & 2. Activity: (Scalability OR Scale up OR Scaling up OR Adoption OR Translational research OR Dissemination \\
OR Interventional /Intervention research OR Diffusion) \\
AND \\
3. Condition type: (Cardiovascular OR Diabetes Mellitus OR Physical Activity OR Obesity OR Nutrition OR Diet \\
OR Smoking OR Smoker OR Smoke OR Exercise OR Physical Inactivity OR Overweight OR Chronic Disease \\
OR Non-communicable disease)
\end{tabular}




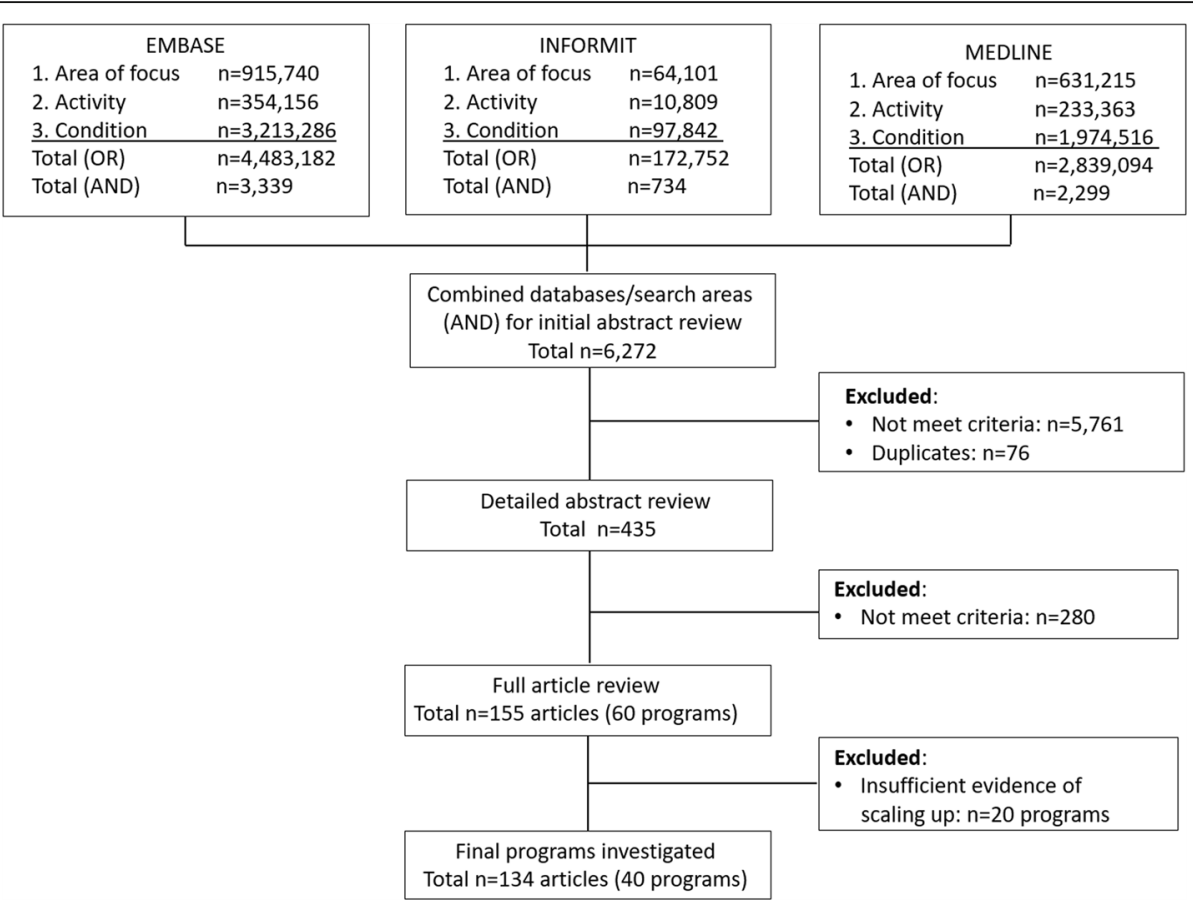

Fig. 1 Literature search results

because there was insufficient evidence of scaling up or there was evidence that scaling up had not occurred; 40 programs were therefore fully investigated for the pathways taken to scaling up.

\section{Documenting program pathways}

The remaining 40 programs were used to characterise the stages from public health program development through to dissemination. From this, a conceptual framework comprising four stages was developed to describe the scaling up process. Each program was mapped to this framework and common pathways were summarised. The characteristics of each program (including the program focus and target population) and documented outcomes were also captured where they could be identified. The outcomes used were derived from Bauman \& Nutbeam [14] and included:

- Institutionalised: evidence that a program had been successfully diffused into a community and integrated into the long-term functions of the host agency or organisation.

- Commercialised: evidence of program developers entering into partnership with private entities and/ or program materials are available for purchase or can be implemented with financial reimbursement.

- Adapted: evidence that the intervention has been adapted or customised for a different population or sub-group.
- Unknown: no further information available on the outcomes of the intervention.

It should be noted that these outcomes were not mutually exclusive as some programs, particularly ones that were implemented in more than one country, fit the definition of more than one category. It should also be noted that these outcomes were mapped using publicly available information so may be incomplete or not up to date. In particular, if a program changed names, it was challenging to determine if it was the same program.

\section{Development of the conceptual framework}

Four primary stages of scaling up were adapted from the public health research translation model for building evidence for public health programs [14] and are outlined in Fig. 2. The first stage identifies the program development process, including whether or not it had a theoretical basis. The second stage identifies whether or not the program underwent pilot testing or was tested in a controlled setting to determine program efficacy. The third stage examines whether the scaling up process included the implementation of a real world trial of the program across multiple settings and locations, which is also described as field testing or replication [14]. The final stage identified whether the program was disseminated at a population level, including whether it was adapted, institutionalised or commercialised. Note that a program may have undergone refinement to improve its effectiveness 


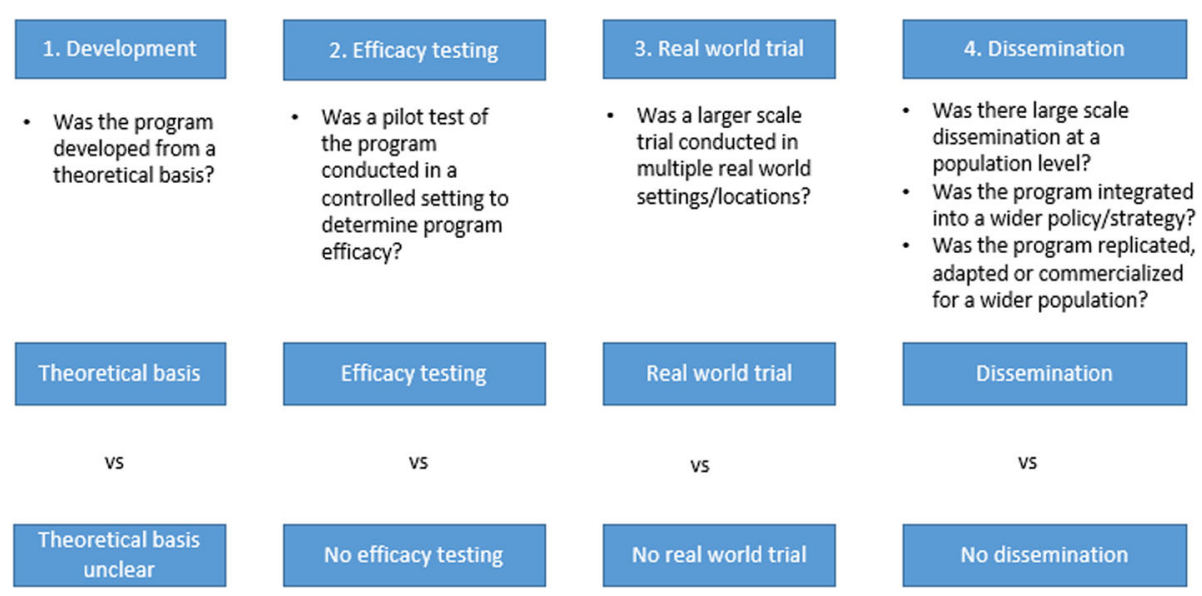

Fig. 2 Scaling up stages

for the target population or setting at any point throughout the four-stage scaling up process. This framework is also similarly aligned to Barker's framework for scaling up interventions in Africa which proposes four stages including 1) Set up; 2) Develop scalable unit; 3) Testing; 4) Go to full-scale [12].

\section{Results}

\section{Program description}

Table 2 provides an overview of the 40 programs identified in this review as being scaled up. It should be noted that these programs do not represent a comprehensive list of all public health intervention programs that have been scaled up, but a sample of chronic disease prevention studies that provide reliable evidence of being scaled up. The majority of the programs $(70 \%)$ were from the United States, followed by Australia (18\%). The primary target populations of the interventions were children and adolescents (43\%), followed by whole population approaches (23\%). Program focus was dominated by physical activity programs (38\%), followed by nutrition $(28 \%)$, health promotion $(23 \%)$ and obesity prevention more broadly (23\%).

\section{Scaling up pathways}

Each of the 40 programs were mapped against the four stages described above to describe the trajectory or pathway taken towards scaling up. For inclusion, all programs had to have evidence of stage 1 (Development) and stage 4 (Dissemination). A summary of the main scaling up pathways is provided in Fig. 3. Each pathway is subsequently described further with examples.

\section{Type I - Comprehensive}

The most common pathway for the 40 programs was 'Type I - Comprehensive' involving adhering to all four stages of scaling up which accounted for $55 \%$ of the programs. An example of a program that followed the 'Type I - Comprehensive' pathway is the Action! Schools $B C$ physical activity and healthy eating program from Canada [15]. As described in Fig. 4, all stages of the scaling pathway were adhered to in the development and dissemination of this program. All scaled up programs that had been implemented in more than one country $(n=5)$ followed the comprehensive pathway.

\section{Type II - Efficacy omitter}

Only two programs (5\%) out of the 40 identified did not have documented evidence of any efficacy testing step, which we have referred to as 'Type II - Efficacy omitters'. An example of this scaling up pathway was Project Energize from New Zealand (Fig. 5) [16]. For these two programs, there was also no evidence of program refinement.

\section{Type III - Trial omitter}

One in four $(25 \%)$ of the 40 scaled up programs were categorised as 'Type III - Trial omitters' where a real world trial was not conducted. Lighten Up to Healthy Lifestyle is an example of a program which appeared to skip the real world trial stage of scaling up (Fig. 6) [17]. Programs which fitted this description were more likely than other scaled up pathways to have multiple program focus areas (such as physical activity and nutrition) and to focus on youth populations.

\section{Type IV - At scale dissemination}

'Type IV - At scale dissemination' involved programs that proceeded directly from development to dissemination, skipping both efficacy testing and real world trials, and typified $15 \%$ of programs. The StrongWomen Program is an example of a program which appeared to follow this trajectory (Fig. 7) [18]. 
Table 2 Scaled up program description

\begin{tabular}{|c|c|c|c|c|c|}
\hline Program Name & Program focus & Target population & Country & Scaling up pathway ${ }^{a}$ & Outcome \\
\hline 5 A day Power Plus [24] & Nutrition & Schools/<18 years & USA & III & Unknown \\
\hline Action Schools! BC [15] & $\begin{array}{l}\text { Multiple: Physical } \\
\text { activity/nutrition }\end{array}$ & Schools $/<18$ years & Canada & । & Institutionalised \\
\hline Active Living Every Day [25] & Physical activity & Whole population & USA & 1 & Commercialised \\
\hline Ageing Well and Healthily [26] & $\begin{array}{l}\text { Multiple: Health } \\
\text { promotion/physical } \\
\text { activity }\end{array}$ & Older adults & Netherlands & 1 & Adapted \\
\hline Ask-Advise-Refer [27] & Smoking cessation & Whole population & USA & I & Institutionalised \\
\hline Body \& Soul [28] & Nutrition & $\begin{array}{l}\text { Other: Faith-based } \\
\text { minority groups }\end{array}$ & USA & । & Unknown \\
\hline $\begin{array}{l}\text { Child and Adolescent Trial } \\
\text { for Cardiovascular Health } \\
\text { (CATCH) [29] }\end{array}$ & Health promotion & Schools $/<18$ years & USA & 1 & $\begin{array}{l}\text { Institutionalised } \\
\text { \& Commercialised }\end{array}$ \\
\hline $\begin{array}{l}\text { Community Health Activities } \\
\text { Model Program for Seniors } \\
\text { (CHAMPS) [30] }\end{array}$ & Physical activity & Older adults & USA & 1 & $\begin{array}{l}\text { Institutionalised } \\
\text { \& Adapted }\end{array}$ \\
\hline $\begin{array}{l}\text { Coronary Health Improvement } \\
\text { Project (CHIP) [31] }\end{array}$ & Health promotion & $\begin{array}{l}\text { Other: People at-risk } \\
\text { of cardiovascular disease }\end{array}$ & $\begin{array}{l}\text { Multiple: USA, } \\
\text { Canada }\end{array}$ & 1 & Commercialised \\
\hline Choice, Control \& Change [32] & $\begin{array}{l}\text { Multiple: Nutrition/ } \\
\text { obesity prevention }\end{array}$ & Schools $/<18$ years & USA & III & Commercialised \\
\hline COACH APPROACH [33] & Physical activity & Whole population & USA & I & Commercialised \\
\hline Color Me Healthy [34] & $\begin{array}{l}\text { Multiple: Physical } \\
\text { activity/nutrition }\end{array}$ & Schools $/<18$ years & USA & IV & Commercialised \\
\hline $\begin{array}{l}\text { Diabetes Prevention Program } \\
\text { (DPP) [35] }\end{array}$ & Health promotion & $\begin{array}{l}\text { Other: People at-risk } \\
\text { of diabetes }\end{array}$ & $\begin{array}{l}\text { Multiple: USA, } \\
\text { Australia, UK }\end{array}$ & I & $\begin{array}{l}\text { Institutionalised } \\
\text { \& Adapted }\end{array}$ \\
\hline $\begin{array}{l}\text { Dutch Obesity Intervention in } \\
\text { Teenagers (DOiT) [36] }\end{array}$ & $\begin{array}{l}\text { Multiple: Health } \\
\text { promotion/obesity } \\
\text { prevention }\end{array}$ & Schools $/<18$ years & Netherlands & III & Unknown \\
\hline Exercise Your Options [37] & $\begin{array}{l}\text { Multiple: Physical } \\
\text { activity/nutrition }\end{array}$ & Schools $/<18$ years & USA & IV & Institutionalised \\
\hline Fit WIC [38] & Obesity prevention & Schools/<18 years & USA & III & Institutionalised \\
\hline Fun 5 [39] & $\begin{array}{l}\text { Multiple: Physical } \\
\text { activity/nutrition }\end{array}$ & Schools/<18 years & USA & III & Institutionalised \\
\hline $\begin{array}{l}\text { Get Healthy Information } \\
\text { and Coaching Service [40] }\end{array}$ & Health promotion & Whole population & Australia & I & Institutionalised \\
\hline $\begin{array}{l}\text { Good Ageing in Lahti Region } \\
\text { (GOAL) Lifestyle Implementation } \\
\text { Trial [41] }\end{array}$ & Health promotion & $\begin{array}{l}\text { Other: People at-risk } \\
\text { of diabetes }\end{array}$ & $\begin{array}{l}\text { Multiple: Finland, } \\
\text { Australia }\end{array}$ & I & Unknown \\
\hline Guided Supermarket Tours [42] & Nutrition & Whole population & Netherlands & $\|$ & Unknown \\
\hline Healthy Together [43] & Health promotion & Whole population & Australia & IV & Institutionalised \\
\hline Hip-Hop to Health [44] & Physical activity & Other: Minority children & USA & I & Commercialised \\
\hline JUMP-in [45] & $\begin{array}{l}\text { Multiple: Physical } \\
\text { activity/obesity } \\
\text { prevention }\end{array}$ & Schools $/<18$ years & Netherlands & III & Unknown \\
\hline $\begin{array}{l}\text { Lighten Up to Healthy } \\
\text { Lifestyle [17] }\end{array}$ & Obesity prevention & Whole population & Australia & III & Institutionalised \\
\hline $\begin{array}{l}\text { Melbourne Diabetes Prevention } \\
\text { Study [46] }\end{array}$ & Health promotion & $\begin{array}{l}\text { Other: People } 50+\text { years } \\
\text { at risk of diabetes }\end{array}$ & Australia & 1 & Institutionalised \\
\hline Mighty Moves [47] & $\begin{array}{l}\text { Multiple: Physical } \\
\text { activity/nutrition }\end{array}$ & Schools $/<18$ years & USA & III & Commercialised \\
\hline $\begin{array}{l}\text { Mind, Exercise, Nutrition... } \\
\text { Do it! (MEND) [48] }\end{array}$ & Health promotion & Schools/<18 years & $\begin{array}{l}\text { Multiple: USA, } \\
\text { Australia, UK }\end{array}$ & 1 & $\begin{array}{l}\text { Institutionalised } \\
\text { \& Adapted }\end{array}$ \\
\hline
\end{tabular}


Table 2 Scaled up program description (Continued)

\begin{tabular}{|c|c|c|c|c|c|}
\hline $\begin{array}{l}\text { MOVE! Weight management } \\
\text { program for Veterans [49] }\end{array}$ & Obesity prevention & Other: Veterans & USA & III & Institutionalised \\
\hline Not on Tobacco (N-O-T) [50] & Smoking cessation & Schools/<18 years & USA & I & Institutionalised \\
\hline Nutrition for Life [51] & Nutrition & Schools/<18 years & USA & IV & Unknown \\
\hline Planet Health [52] & Obesity prevention & Schools/<18 years & USA & I & Institutionalised \\
\hline Project Energize [16] & $\begin{array}{l}\text { Multiple: Physical } \\
\text { activity/obesity } \\
\text { prevention }\end{array}$ & Schools/<18 years & New Zealand & $\|$ & $\begin{array}{l}\text { Institutionalised } \\
\text { \& Adapted }\end{array}$ \\
\hline Shaping Up My Choices [53] & Nutrition & Schools/<18 years & USA & I & Institutionalised \\
\hline $\begin{array}{l}\text { Sports, Play, and Active } \\
\text { Recreation for Kids } \\
\text { (SPARK) [54] }\end{array}$ & Physical activity & $\begin{array}{l}\text { Schools Schools/ } \\
<18 \text { years }\end{array}$ & USA & । & Institutionalised \\
\hline Staying Free [55] & Smoking cessation & $\begin{array}{l}\text { Other: Smokers in } \\
\text { acute care settings }\end{array}$ & $\begin{array}{l}\text { Multiple: USA, } \\
\text { Canada }\end{array}$ & । & Adapted \\
\hline Strong for Life [56] & Physical activity & Older adults & USA & I & Commercialised \\
\hline StrongWomen Program [18] & Physical activity & $\begin{array}{l}\text { Other: Women } \\
\text { ( } 40+\text { years) }\end{array}$ & USA & IV & Institutionalised \\
\hline Take 10! [57] & Physical activity & Schools/<18 years & USA & III & Institutionalised \\
\hline Txt2Stop [58] & Smoking cessation & Whole population & UK & । & Unknown \\
\hline Walk Kansas [59] & Physical activity & Whole population & USA & IV & Institutionalised \\
\hline
\end{tabular}

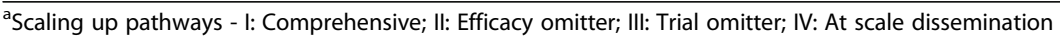

\section{Outcomes}

The final outcome of the dissemination process resulted in $55 \%(N=22)$ of the programs being institutionalised (4 of which were also adapted for specific populations and 1 also commercialised), $20 \%(N=8)$ of the programs being commercialised, a further $5 \%(N=2)$ were adapted and the remaining $20 \%(N=8)$ had an unknown outcome. There were no differences in the outcomes when reviewed for each scaling up pathway (see Table 3 below). Other program characteristics, such as country of implementation, were more strongly associated with outcome; for example, $100 \%$ of programs that were commercialised had been implemented in the United States.

Additionally, just under half (43\%) of the programs had a documented refinement process such as the RE-
AIM (Reach Effectiveness - Adoption Implementation Maintenance) framework [19]. RE-AIM and similar frameworks encourage program planners to examine program reach, intervention effectiveness and contextual factors that can improve the sustainable adoption and implementation of interventions. The application of the RE-AIM refinement process may have assisted these programs in achieving improved outcomes.

\section{Discussion}

This, to the authors' knowledge, is the first study to describe and classify the typical pathways through which a diverse range of public health interventions in real world settings are scaled up to reach the broader population. This study builds on previous research which has focused

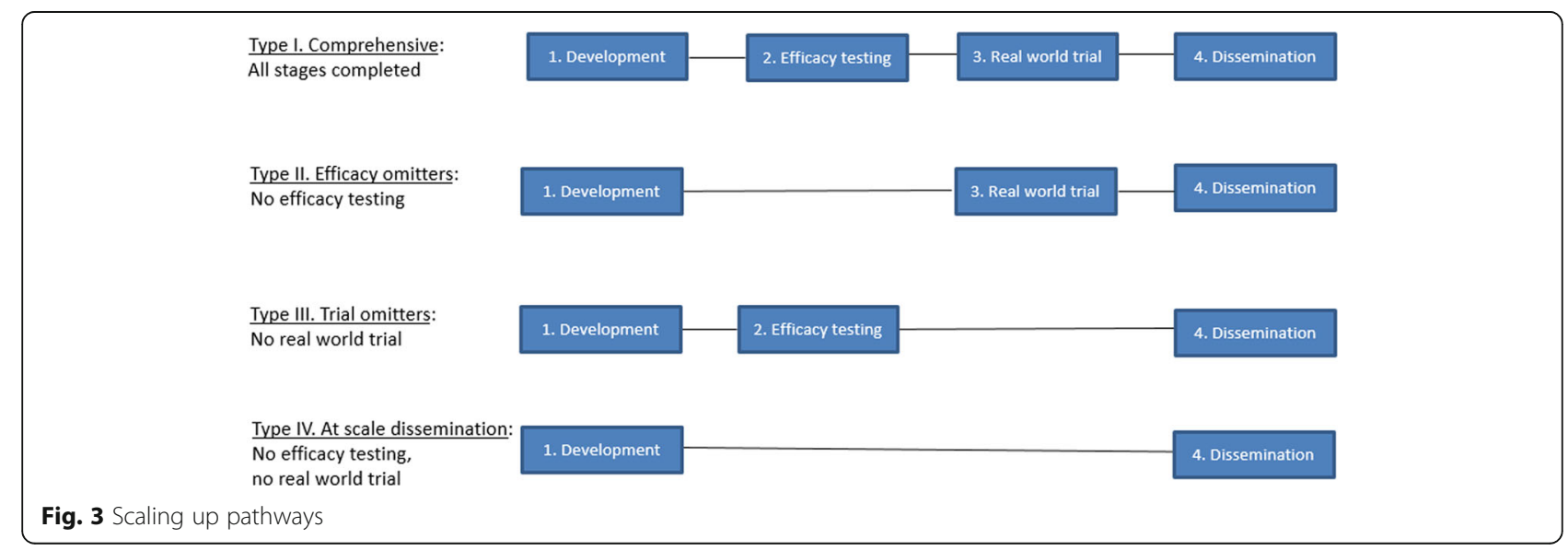




\begin{tabular}{|c|c|c|c|}
\hline 1. Development & 2. Efficacy testing & 3. Real world trial & 4. Dissemination \\
\hline $\begin{array}{l}\text { AS!BC is a } \\
\text { comprehensive school } \\
\text { based model that } \\
\text { promotes physical } \\
\text { activity (PA) and } \\
\text { healthy eating (HE) in } \\
\text { elementary schools in } \\
\text { BC Canada. It was } \\
\text { developed in } 2002 \text { and } \\
\text { is based on socio- } \\
\text { ecological theory and } \\
\text { partnership approach } \\
\text { to social change. }\end{array}$ & $\begin{array}{l}\text { A cluster randomised } \\
\text { controlled trial was } \\
\text { conducted with } 10 \\
\text { schools (2003/04) for } \\
\text { period of } 16 \text { months } \\
\text { to establish efficacy of } \\
\text { the PA component. A } \\
\text { new component } \\
\text { 'Healthy Eating' was } \\
\text { developed to further } \\
\text { address concerns of } \\
\text { obesity and unhealthy } \\
\text { eating patterns. (2007) }\end{array}$ & $\begin{array}{l}\text { Effectiveness of the PA } \\
\text { component was tested } \\
\text { through another } \\
\text { cluster RCT with } 4 \\
\text { schools over a } 2 \text { year } \\
\text { period (2005-2007). } \\
\text { Efficacy of HE } \\
\text { component was } \\
\text { conducted with } 10 \\
\text { schools over } 16 \\
\text { months (2006/07) in } \\
\text { two phases. }\end{array}$ & $\begin{array}{c}\text { Funding was provided } \\
\text { by the BC government } \\
\text { for state-wide } \\
\text { dissemination of } \\
\text { AS!BC (2004/05) with } \\
702 \text { schools having } \\
\text { implemented AS!BC. } \\
\text { As part of } \\
\text { institutionalisation } \\
\text { process, guidelines } \\
\text { and policies for } \\
\text { implementation were } \\
\text { developed for schools. }\end{array}$ \\
\hline
\end{tabular}

Fig. 4 Comprehensive case study: Action! Schools BC, Canada

on developing guidance on best practice scale up frameworks [10-13]. The 'Type I - Comprehensive' four-stage evidence pathway described in our conceptual model starts with program development and moves into efficacy testing, conducting a real world trial and finally population-wide dissemination mirrors key steps widely advocated in scale up frameworks proposed in both high income [10, 11] and low-middle income contexts [12]. However, the typology developed and applied in the current study to 40 scaled up public health programs, demonstrates that the process of scaling up can be variable in its use of evidence and does not always follow a linear pathway. Many of these interventions reported using a structured refinement process, such as the REAIM framework $[1,12,19]$ and the most common pathway, taken in over half of interventions reviewed, was described as the 'Type I - Comprehensive' pathway, where all the stages were adhered to. What is still unclear is whether adherence to all four stages proposed in many frameworks [10-12] results in greater success in population reach and better sustainability, with no clear association identified between scaling up pathways and program outcomes.

The scaling up pathway which occurred the least often (5\% of interventions identified) was 'Type II - Efficacy omitters' where efficacy testing in a controlled setting did not appear to take place before a real world trial was conducted. It is possible that for these interventions, efficacy testing did take place but the findings were not published or accessible. Alternatively, it may be that funding was available to implement the program quickly in a real world trial and efficacy testing was not conducted for expediency. Whatever the underlying reason, scaling up an intervention without evidence of its effectiveness must be weighed up against the potential benefits of enabling a broader population to have access to the intervention in a real world trial.

One quarter of interventions were found to omit a real world effectiveness trial or replication studies ('Type III - Trial omitters'), and progressed directly from efficacy testing to widespread dissemination. One explanation for this pathway is that once an intervention has been demonstrated to be effective in

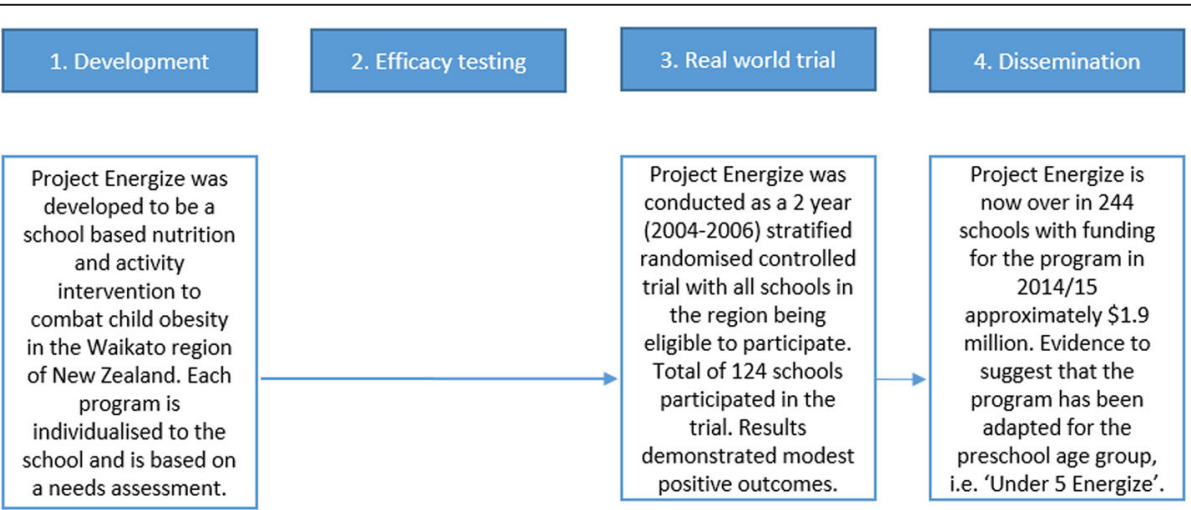

Fig. 5 Efficacy omitters case study: Project Energize, New Zealand 


\begin{tabular}{|c|c|c|c|}
\hline 1. Development & 2. Efficacy testing & 3. Real world trial & 4. Dissemination \\
\hline $\begin{array}{l}\text { Lighten Up to Healthy } \\
\text { Lifestyle (LUHL) seeks } \\
\text { to establish a } \\
\text { proactive and } \\
\text { supportive community } \\
\text { health infrastructure } \\
\text { to assist in addressing } \\
\text { overweight as a } \\
\text { community health } \\
\text { issue. It was } \\
\text { developed based on } \\
\text { the trans-theoretical } \\
\text { model of behaviour } \\
\text { change. }\end{array}$ & $\begin{array}{c}\text { LUHL when developed } \\
\text { was primarily a weight } \\
\text { loss program and was } \\
\text { trialled in } 7 \text { rural } \\
\text { communities in } \\
\text { Queensland (1990) } \\
\text { within a primary } \\
\text { health care setting. } \\
\text { Since the initial trial, } \\
\text { the LUHL was revised } \\
\text { with a broader } \\
\text { emphasis on } \\
\text { promoting healthy } \\
\text { lifestyle changes. }\end{array}$ & & $\begin{array}{l}\text { In 2004, LUHL was } \\
\text { disseminated to } 20 \\
\text { Health districts } \\
\text { statewide in } \\
\text { Queensland and is still } \\
\text { currently in operation. }\end{array}$ \\
\hline
\end{tabular}

Fig. 6 Trial omitters case study: Lighten Up to Healthy Lifestyle, Australia

a controlled setting, policy-makers may wish to disseminate it widely rather than wait for the intervention to undergo another level of testing in a real world trial [3]. This can be a risky approach as intervention effects have been observed to drop from efficacy studies to effectiveness studies and drop further when implemented at scale [1]. Without testing in a real world setting, there is potential for the intervention to be less effective and decrease its potential benefits for the target population. Effectiveness studies in a real world setting enable the intervention to be assessed in a broader patient population, across a wider geographic area and in different clinical settings which can improve the external validity of the intervention [20].

Surprisingly, nearly one in seven (15\%) interventions were identified as 'Type IV - At scale dissemination' which described where the program went directly from the development stage to populationthe-wide dissemination, omitting both evidence generating stages of efficacy testing or real world trials. Programs in this category may have been implemented rapidly due to policy pressures, causing a shortened timescale for dissemination. The pressure for policy makers to act with imperfect evidence is widely reported [3]. As a policy maker responsible for scaling public health interventions recently noted in qualitative research study that examined scale up decision making: 'Plenty of critics were happy to say "well it's never been done before, how do you know it will work?" That's the reality of any large scale population based intervention. Someone has to do it first...' [3]. This approach is not without its risks, most obvious of which is that an ineffective intervention may be scaled up. Further qualitative research would be needed to gain a better understanding of why this approach is taken by program developers and the implications for program delivery and outcomes.

Although this is presented as a four-stage model, it was clear that the final stage of "dissemination" was not static but could sometimes involve further refinement and adaptation including translation for adoption by a range of subpopulations and across different countries

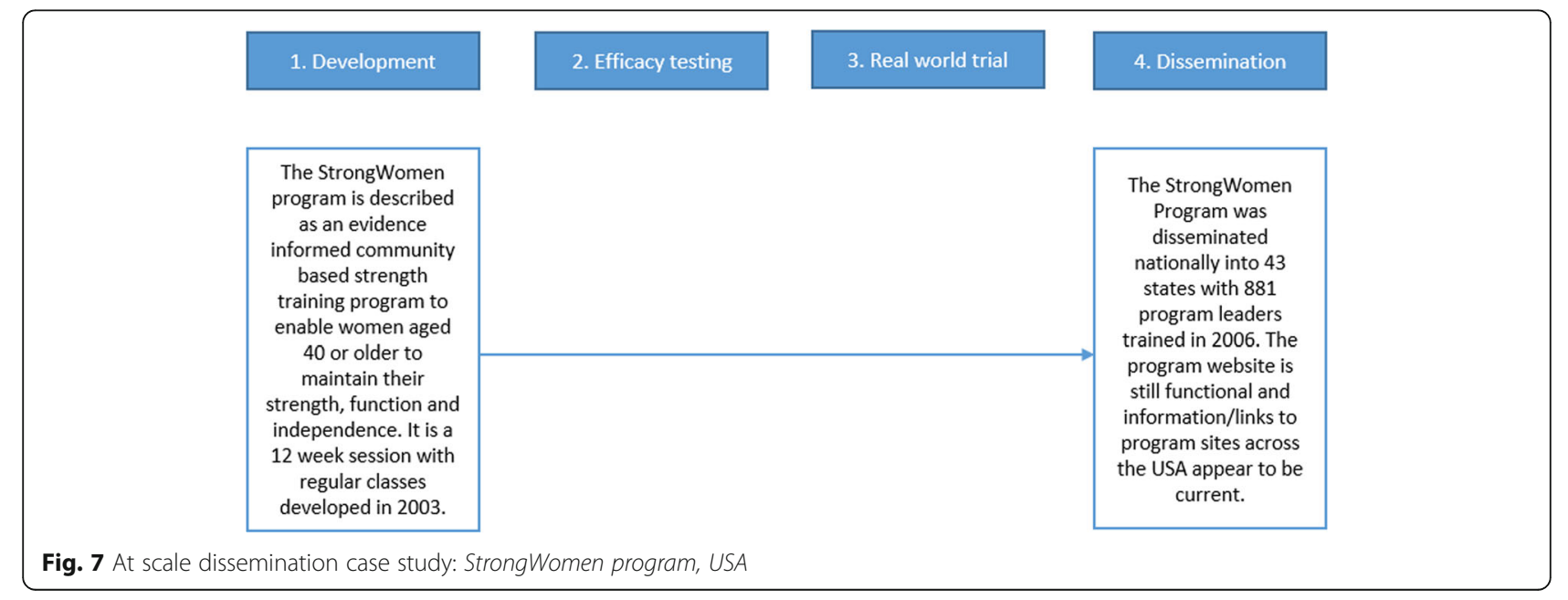


Table 3 Scaled up program pathways by outcomes

\begin{tabular}{llllll}
\hline Outcome & Type I Comprehensive \% (N) & $\begin{array}{l}\text { Type II Efficacy } \\
\text { omitter \% (N) }\end{array}$ & $\begin{array}{l}\text { Type III Trial } \\
\text { omitter \% (N) }\end{array}$ & $\begin{array}{l}\text { Type IV At scale } \\
\text { dissemination \% (N) }\end{array}$ & \begin{tabular}{l} 
Total (all programs) \% (N) \\
\hline Institutionalised
\end{tabular} \\
Institutionalised \& Adapted & $36.4(8)$ & $0.0(0)$ & $50.0(5)$ & $66.7(4)$ & $42.5(17)$ \\
Institutionalised \& Commercialised & $13.6(3)$ & $50.0(1)$ & $0.0(0)$ & $0.0(0)$ & $10.0(4)$ \\
Commercialised & $22.7(5)$ & $0.0(0)$ & $0.0(0)$ & $0.0(0)$ & $2.5(1)$ \\
Adapted & $9.1(2)$ & $0.0(0)$ & $20.0(2)$ & $16.7(1)$ & $20.0(8)$ \\
Unknown & $13.6(3)$ & $0.0(0)$ & $0.0(0)$ & $0.0(0)$ & $5.0(2)$ \\
Total & $100.0(22)$ & $50.0(1)$ & $30.0(3)$ & $16.7(1)$ & $20.0(8)$ \\
\hline
\end{tabular}

[21]. Just under half (45\%) of programs became institutionalised [14] or embedded into routine procedures or curricula. Even the term "at scale" varied as to size; some programs were disseminated across a city or region, whereas others (such as the MEND school-based health promotion program) were taken up in multiple countries [22]. Hence while we believe that these characterisations form a useful framework for examining, describing and assessing the scaling up process, clearly there is much detail and variability underlying each stage and pathway through the stages not explicitly captured by the pathways.

A primary limitation of this study is that it relied upon available published information to document the trajectory a program followed for scaling up and its outcome, which may have resulted in publication bias as a result of excluding gray literature sources. Additionally, the outcome of the programs identified (institutionalised, commercialised, etc) is an indicator of the sustainability of the program and cannot be used to determine program effectiveness in achieving its public health outcomes. Articles not published in English were also excluded which may have resulted in a language bias. Efficacy testing and real world trials may have been conducted and programs widely disseminated but not published or made available externally. Further, as programs were refined, they may have changed their name or combined with other programs, making it difficult to establish program boundaries and subsequently to identify pathways of development. Further research should be conducted that includes interviews with key stakeholders in the program development and scaling up process to develop a clearer picture of the timeframes, pathways taken and impact of the scaling up pathway on the final outcome. Further, the proportions here are based on the sample of case studies extracted around chronic disease risk factor interventions, and may not apply to other scale up areas. Nonetheless, the principles and pathways are likely to be similar, and their classification provides guidance for policymakers and practitioners in characterising scaled up population-level intervention research.

This research has identified four potential pathways that a public health intervention may follow from program development to population-wide dissemination. Developing such a classification system helps researchers and policy makers alike to better understand the stages and pathways public health interventions follow in practice in scaling up. However, in order to improve the utility of this framework, the outcomes and sustainability of programs who adhere to the different pathways should be assessed to determine their relative success. This may help to inform policymakers seeking to urgently implement programs with insufficient evidence of the risks and benefits of doing so. It would also be important to investigate whether the scaling up pathways vary by the nature of the intervention (i.e., education program, behaviour change etc.) or by the structural characteristics of the organisations funding or the methods used to implement the scaling up process. These contextual factors are an important characteristic to take into account when considering rationales and implications of scaling up pathways followed [23].

\section{Conclusions}

The study demonstrates that the scale up of public health interventions often follows a range of pathways which are informed by differing levels of intervention evidence. Understanding these pathways contributes to a better appreciation of the role that evidence plays in the successful scale up of public health interventions. The policy and practice determinants leading to each pathway merit further study as does the relative success of these trajectories.

Abbreviation

RE-AIM: Reach Effectiveness - Adoption Implementation Maintenance

\section{Acknowledgements}

We wish to thank The Australian Prevention Partnership Centre (including its funding partners National Health and Medical Research

Council, the Australian Government Department of Health, NSW Ministry of Health, ACT Health and the HCF Research Foundation) for supporting and funding this research.

\section{Funding}

This work was funded by the National Health and Medical Research Council of Australia (NHMRC) through its partnership centre grant scheme (Grant ID: GNT9100001). NSW Health, ACT Health, The Commonwealth Department of Health, The Hospitals Contribution Fund of Australia, and HCF Research Foundation have contributed funds to support this work as part of the NHMRC partnership centre grant scheme. 


\section{Availability of data and materials}

Not applicable.

\section{Author's contributions}

$\mathrm{AB}$ led the conception of the paper. DI drafted the manuscript. $\mathrm{KL}$ conducted the literature search and categorised the programs. AG assisted with the culling of the articles and drafting of the manuscript. AM led the development of the conceptual framework. All authors have made important intellectual contributions to multiple draft revisions. All authors read and approved the final manuscript.

\section{Ethics approval and consent to participate}

Not applicable.

\section{Consent for publication}

Not applicable.

\section{Competing interests}

The authors declare that they have no competing interests.

\section{Publisher's Note}

Springer Nature remains neutral with regard to jurisdictional claims in published maps and institutional affiliations.

\section{Author details}

'The Australian Prevention Partnership Centre and School of Public Health, University of Sydney, Sydney, Australia. ${ }^{2}$ School of Public Health, University of Sydney, Sydney, Australia. ${ }^{3}$ Centre for Epidemiology and Evidence, New South Wales Ministry of Health, 73 Miller Street, North Sydney NSW, Sydney 2060, Australia.

\section{Received: 19 August 2016 Accepted: 6 July 2017}

\section{Published online: 01 August 2017}

\section{References}

1. Milat AJ, King L, Bauman A, Redman S. The concept of scalability: increasing the scale and potential adoption of health promotion interventions into policy and practice. Health Promot Int. 2013;28(3):285-98.

2. World Health Organization and ExpandNet. Nine steps for developing a scaling-up strategy. 2010, WHO: Geneva.

3. Milat AJ, Newson R, Wolfenden L, Rissel C, Bauman A, Redman S. Increasing the scale and adoption of population health interventions: experiences and perspectives of policy-makers, practitioners and researchers. Health Research Policy and Systems. 2014:12:18.

4. Milat AJ, Bauman A, Redman S, Curac N. Public health research outputs from efficacy to dissemination: a bibliometric analysis. BMC Public Health. 2011;11:934

5. Pérez-Escamilla R, Curry L, Minhas D, Taylor L, Bradley E. Scaling up of breastfeeding promotion programs in low-and middle-income countries: the "breastfeeding gear" model. Advances in Nutrition: An International Review Journal. 2012;3(6):790-800.

6. Yamey G. Scaling up global health interventions: a proposed framework for success. PLoS Med. 2011;8(6):e1001049.

7. Kohl R, Cooley L. Scaling up-a conceptual and operational framework. Washington, DC: Management Systems International; 2003.

8. Victora CG, Barros FC, Assuncao MC, Restrepo-Mendez MC, Matijasevich A, Martorell R. Scaling up maternal nutrition programs to improve birth outcomes: implementation issues. Food Nutr Bull. 2012;33(2):S6.

9. Bhandari N, Kabir AKM, Salam MA. Mainstreaming nutrition into maternal and child health programmes: scaling up of exclusive breastfeeding. Maternal \& Child Nutrition. 2008:4(s1):5-23.

10. Milat AJ, Newsom R, King L. Increasing the scale of population health interventions: a guide. NSW Ministry of Health: North Sydney; 2014.

11. Milat AJ, Newson R, King L, Rissel C, Wolfenden L, Bauman A, Redman S, Giffin M. A guide to scaling up population health interventions. Public Health Research \& Practice. 2016:26(1):e2611604.

12. Barker PM, Reid A, Schall MW. A framework for scaling up health interventions: lessons from large-scale improvement initiatives in Africa. Implement Sci 2016;11(1):1.

13. Simmons R, Fajans P, Ghiron L. Scaling up health service delivery: from pilot innovations to policies and programmes: World Health Organization; 2007.
14. Bauman A, Nutbeam D. Evaluation in a nutshell: a practical guide to the evaluation of health promotion programs: McGraw Hill; 2013.

15. McKay HA, Macdonald HM, Nettlefold L, Masse LC, Day M, Naylor PJ. Action schools! BC implementation: from efficacy to effectiveness to scale-up. $\mathrm{Br}$ J Sports Med. 2015;49:210-8.

16. Rush E, Reed P, McLennan S, Coppinger T, Simmons D, Graham D. A school-based obesity control programme: project energize two-year outcomes. Br J Nutr. 2012;107:581-7.

17. Harvey PW, Steele J, Bruggemann JN, Jeffery RW. The development and evaluation of lighten up, an Australian community-based weight management program. Am J Health Promot. 1998;13(1):8-11.

18. Seguin RA, Economos CD, Hyatt R, Palombo R, Reed P, Nelson M. Design and national dissemination of the StrongWomen community strength training program. Public Health Research, Practice and Policy. 2008;5(1):1-13.

19. Dzewaltowski DA, Glasgow RE, Klesges LM, Estbrooks PA, Brock E. RE-AIM: evidence-based standards and a web resource to improve translation of research into practice. Annals of Behavioural Medicine. 2004:28(2):75-80.

20. Nallamothu BK, Hayward RA, Bates ER. Beyond the randomised clinical trial: the role of effectiveness studies in evaluating cardiovascular therapies. Circulation. 2008;1 18:1294-303.

21. O'Hara BJ, Phongsavan P, King L, Develin E, Milat AJ, Eggins D, King E, Smith J, Bauman AE. Translational formative evaluation: critical in up-scaling public health programmes. Health Promot Int. 2014;29(1):38-46.

22. Fagg J, Chadwick P, Cole TJ, Cummins S, Goldstein H, Lewis H, et al. From trial to population: a study of family-based community intervention for childhood obesity implemented at scale. Int J Obes. 2014;38:1343-9.

23. Paina $\mathrm{L}$, Peters $\mathrm{DH}$. Understanding pathways for scaling up health services through the lens of complex adaptive systems. Health Policy and Planing. 2012;27(5):363-73.

24. Story M, Mays RW, Bishop DB, Perry CL, Taylor G, Smyth G, et al. 5-a-day power plus: process evaluation of a multicomponent elementary school program to increase fruit and vegetable consumption. Health Educ Behav 2000;27(2):187-200.

25. Dunn AL, Buller DB, Dearing JW, Cutter G, Guerra M, Wilcox S, et al. Adopting an evidence-based lifestyle physical activity program: dissemination study design and methods. Translational Behavioural Medicine. 2012;2:199-208.

26. Westhoff MH, Hopman-Rock M. Dissemination and implementation of 'ageing well and healthily': a health education and exercise program for older adults. J Aging Phys Act. 2002;10:382-95.

27. Patwardhan P, Chewning BA. Effectiveness of intervention to implement tobacco cessation counseling in community chain pharmacies. Journal of the American Pharmacists Association. 2012;52:507-14.

28. Allicock M, Campbell MK, Valle CG, Carr C, Resnicow K, Gizlice Z. Evaluating the dissemination of Body \& Soul, an evidence-based fruit and vegetable intake intervention: challenges for dissemination and implementation research. J Nutr Educ Behav. 2012;44(6):530-8.

29. Hoelscher DM, Kelder SH, Murray N, Cribb PW, Conroy J, Parcel GS. Dissemination and adoption of the child and adolescent trial for cardiovascular health (CATCH): a case study in Texas. Journal Public Health Management Practice. 2001;7(2):90-100.

30. Stewart AL, Gillis D, Grossman M, Castrillo M, Pruitt L, McLellan B, et al. Diffusing a research-based physical activity promotion program for seniors into diverse communities: CHAMPS III. Public Health Research, Practice and Policy. 2006;3(2):1-16.

31. Morton DP, Rankin P, Morey P, Kent L, Hurlow T, Chang E, et al. The effectiveness of the complete health improvement program (CHIP) in Australasia for reducing selected chronic disease risk factors: a feasibility study. N Z Med J. 2013;126(1370):43-54

32. Contento IR, Koch PA, Heewon L, Calabrese-Barton A. Adolescents demonstrate improvement in obesity risk behaviors after completion of Choice, Control \& Change, a curriculum addressing personal agency and autonomous motivation. J Am Diet Assoc. 2010;110:1830-9.

33. Annesi JJ, Unruh J. Effects of the Coach approach intervention on drop-out rates among adults initiating exercise program at nine YMCAs over three years. Percept Mot Skills. 2007;104:459-66.

34. Dunn C, Thomas C, Ward D, Pegram L, Webber K, Cullitan C. Design and implementation of a nutrition and physical activity curriculum for child care settings. Public Health Research, Practice and Policy. 2006;3(2):1-8.

35. Oldenburg B, Absetz P, Dunbar JA, Reddy P, O'Neill A. The spread and uptake of diabetes prevention programs around the world: a case study from Finland and Australia. Translational Behavioural Medicine. 2011;1:270-82. 
36. Van Nassau F, Singh AS, van Mechelen W, Brug J, Chinapaw M. In preparation of the nationwide dissemination of the school-based obesity prevention program DOiT: stepwise development applying the intervention mapping protocol. Journal of School Health.2014:84(8):481-92.

37. Dunton GF, Lagliore R, Robertson T. Using the RE-AIM framework to evaluate the statewide dissemination of a school-based physical activity and nutrition curriculum: "Exercise Your Options." Am J Health Promot 2009; 23(4):229-232.

38. Sekhobo JP, Egglefield K, Edmunds LS, Shackman G. Evidence of the adoption and implementation of a statewide childhood obesity prevention initiative in the New York state WIC program: the NY Fit WIC process evaluation. Health Education and Research. 2012;27(2):281-91.

39. Nigg C, Geller K, Adams P, Hamada M, Hwang P, Chung R. Successful dissemination of fun 5 - a physical activity and nutrition program for children. Translational Behavioural Medicine. 2012;2:276-85.

40. O'Hara BJ, Phongsavan P, Venugopal K, Eakin EG, Eggins D, Caterson H, et al. Effectiveness of Australia's get healthy information and coaching service: translational research with population wide impact. Prev Med. 2012:55:292-8.

41. Laatikainen T, Dunbar JA, Chapman A, Kilkkinen A, Vartiainen E, Heistaro S, et al. Prevention of type 2 diabetes by lifestyle intervention in an Australian primary health care setting: greater green triangle (GGT) diabetes prevention project. BMC Public Health. 2007;7:249.

42. Van Assema P, Brug J, Glanz K, Dolders M, Mudde A. Nationwide implementation of guided supermarket tours in the Netherlands: a dissemination study. Health Education and Research. 1998;13(4):557-66.

43. Foulkes C. Systems interventions to halt and reverse rising trends in obesity what theories, methodologies and methods actually aid practice: cases from healthy together Geelong. Obesity Research \& Clinical Practice. 2014:8(1):33-4.

44. Buscemi J, Odoms-Young A, Stolley ML, Blumstein L, Schiffer L, Berbaum $\mathrm{ML}$, et al. Adaptation and dissemination of an evidence-based obesity prevention intervention: design of a comparative effectiveness trial. Contemporary Clinical Trials. 2014;38(2):355-60.

45. De Meij JSB, van der Wal MF, van Mechelen W, Chinapaw MJM. A mixed method process evaluation of the implementation of JUMP-in, a multi-level school-based intervention aimed at physical activity promotion. Health Promot Pract. 2013;14(5):777-90.

46. Janus ED, Best JD, Davis-Lameloise N, Philpot B, Hernan A, Bennett CM, et al. Scaling-up from an implementation trial to state-wide coverage: results from the preliminary Melbourne diabetes prevention study. Trials. 2012;13:152.

47. Bellows $L$, Anderson J. The food friends get movin' with Mighty Moves: a physical activity program for preschoolers. J Nutr Educ Behav. 2013;45(5):473-5.

48. Fagg J, Chadwick P, Cole TJ, Goldstein H, Lewis H, Morris S, et al. From trial to population: a study of a family-based community intervention for childhood overweight implemented at scale. Int J Obes. 2014;38:1343-9.

49. Kinsinger LS, Jones KR, Kahwati L, Harvey R, Burdick M, Zele V, et al. Design and dissemination of the MOVE! Weight-management program for veterans. Public Health Research, Practice and Policy. 2009;6(3):1-6.

50. Franks AL, Kelder SH, Dino GA, Horn KA, Gortmaker SL, Wiecha JL, et al. School-based programs: lessons learned from $\mathrm{CATCH}$, planet health and not-on-tobacco. Public Health Research, Practice and Policy. 2007:4(2):1-9.

51. Olson CM, Devine CM, Frongillo EA. Dissemination and use of a schoolbased nutrition education program for secondary school students. J Sch Health. 1993:63(8):343-8.

52. Wiecha JL, El Ayadi AM, Fuemmeler BF, Carter JE, Handler S, Johnson S, et al. Diffusion of an integrated health education program in an urban school system: planet health. J Pediatr Psychol. 2004;29(6):467-74.

53. Dunton GF, Liao Y, Grana R, Lagliore R, Riggs N, Chou CP, et al. State-wide dissemination of a school-based nutrition education programme: a RE-AIM (reach, efficacy, adoption, implementation, maintenance) analysis. Public Health Nutr. 2012;17(2):422-30.

54. McKenzie TL, Sallis JF, Rosengard P. Beyond the stucco tower: design, development and dissemination of the SPARK physical education programs. Quest. 2009;61:114-27.

55. Taylor CB, Miller NH, Cameron RP, Fagans EW, Das S. Dissemination of an effective inpatient tobacco use cessation program. Nicotine Tob Res. 2005; 7(1):129-37.

56. Etkin CD, Prohaska TR, Harris BA, Lathan N, Jette A. Feasibility of implementing the strong for life program in community settings. The Gerontologist. 2006;46(2):284-92.
57. Kibbe DL, Hackett J, Hurley M, McFarland A, Schubert KG, Schultz A, et al. Ten years of take 10!: integrating physical activity with academic concepts in elementary school classrooms. Prev Med. 2011;52:\$43-50.

58. Michie S, Free C, West R. Characterising the 'Txt2stop' smoking cessation text messaging intervention in terms of behaviour change techniques. J Smok Cessat. 2012;7(1):55-60.

59. Estabrooks PA, Bradshaw M, Dzewaltowski DA. Smith-ray RL. Determining the impact of Walk Kansas: applying a team-building approach to community physical activity promotion. 2008;36:1-12.

\section{Submit your next manuscript to BioMed Central and we will help you at every step:}

- We accept pre-submission inquiries

- Our selector tool helps you to find the most relevant journal

- We provide round the clock customer support

- Convenient online submission

- Thorough peer review

- Inclusion in PubMed and all major indexing services

- Maximum visibility for your research

Submit your manuscript at www.biomedcentral.com/submit
) Biomed Central 